\title{
Kesejahteraan Subjektif Mahasiswa dimasa Pandemi Covid-19
}

\author{
${ }^{1}$ Naila Kamaliya, ${ }^{2}$ Hari Setyowibowo , ${ }^{3}$ Surya Cahyadi \\ ${ }^{123}$ Fakultas Psikologi, Universitas Padjadjaran \\ Email Korespondensi: naila19003@mail.unpad.ac.id
}

\begin{abstract}
Implementing physical distancing to reduce the spread of COVID-19 has affected all segments of society including students. The Indonesian government suspended face-to-face learning activity and replaced it with online learning at universities affected by COVID-19. The sudden change in activity might as well have an impact on students, such as their subjective well-being. This study examined students' subjective well-being during the COVID-19 pandemic using a descriptive quantitative approach. A total of 112 students participated from eight islands spread across Indonesia, and were chosen through accidental sampling technique. Instruments used were Satisfaction With Life Scale (SWLS) and Positive and Negative Affect Scale (PANAS). The data obtained was analyzed using univariate descriptive quantitative analysis. The results showed that the majority of respondents in this study $(\mathrm{N}=112)$ had moderate subjective well-being (53.6\%), low subjective well-being (17.9\%), and high subjective wellbeing $(28.6 \%)$. These results indicate that many students evaluate their lives quite positively, that is, they feel quite satisfied with their lives and are balanced in feeling positive and negative emotions. In addition, the majority of students had moderate life satisfaction dimension (53.6\%), high domain satisfaction dimension (64.3\%), high positive affect dimension (54.5\%), and equally moderate and low negative affect dimension with the same percentage each $(36.6 \%)$. This study provides scientific information as a basis for student empowerment programs to be more resilient and adaptive during and after the COVID-19 pandemic.
\end{abstract}

Keywords: Subjective Well-Being, College Students, COVID-19

Abstrak. Pemberlakuan jaga jarak fisik untuk mengurangi penyebaran Covid-19 telah berdampak pada seluruh lapisan masyarakat termasuk mahasiswa. Pemerintah Indonesia menghentikan aktivitas pembelajaran tatap muka dan diganti dengan pembelajaran daring pada perguruan tinggi yang terdampak Covid-19. Perubahan aktivitas secara tiba-tiba memungkinkan untuk berdampak pada kondisi mahasiswa pula, seperti keadaan kesejahteraan subjektif mahasiswa. Penelitian ini membahas mengenai gambaran atau keadaan kesejahteraan subjektif mahasiswa dimasa pandemi Covid-19 dengan menggunakan pendekatan kuantitatif deskriptif. Partisipan penelitian ini melibatkan 112 mahasiswa yang tersebar pada delapan pulau di Indonesia, dan diambil melalui teknik accidental sampling. Instrumen penelitian menggunakan Satisfaction With Life Scale (SWLS) dan Positive and Negative Affect Scale (PANAS). Analisis data menggunakan analisis kuantitaif deskriptif univariat. Hasil penelitian menunjukkan bahwa responden dalam penelitian ini $(\mathrm{N}=112)$ paling banyak memiliki skor kesejahteraan subjektif pada kategori sedang $(53,6 \%)$, rendah (17.9\%), dan tinggi (28.6\%). Hasil ini menunjukkan bahwa banyak mahasiswa yang mengevaluasi kehidupannya cukup positif, yaitu merasa cukup puas dengan kehidupannya serta seimbang dalam merasakan emosi positif dan negatif. Selain itu, mayoritas mahasiswa berada dikategori sedang pada dimensi life satisfaction (53,6\%), kategori tinggi pada dimensi domain satisfaction (64,3\%), kategori tinggi pada dimensi positive affect (54,5\%), pada dimensi negative affect mayoritas berada pada kategori sedang dan rendah dengan prosentase yang sama $(36,6 \%)$. Penelitian ini diharapkan mampu memberikan informasi ilmiah sebagai landasan untuk program pemberdayaan mahasiswa agar lebih tangguh dan adaptif selama dan pasca pandemi Covid-19.

Kata kunci: Kesejahteraan subjektif, mahasiswa, Covid-19

\section{PENDAHULUAN}

Pandemi Coronavirus Disease 2019 (Covid-19) tengah dialami oleh berbagai negara diseluruh dunia (WHO, 2020). Langkah-langkah pencegahan terus dikampanyekan untuk memperkecil resiko penyebaran Covid-19, salah satunya adalah dengan menjaga jarak fisik (WHO, 2020). Aturan tersebut menyebabkan berbagai rutinitas sehari-hari terganggu, salah satunya 
adalah rutinitas pembelajaran di perguruan tinggi. Menurut UNESCO sebanyak 1,3 juta pelajar di dunia masih terdampak akibat penutupan sekolah dan universitas dimasa pandemi Covid-19 (UNESCO, 2020). Penutupan perguruan tinggi juga terjadi di Indonesia, pemerintah Indonesia menetapkan penghentian sementara kegiatan akademik seperti perkuliahan secara tatap muka, kemudian menggantinya menjadi perkuliahan dalam jaringan (daring) (Kemendikbud, 2020a).

Penutupan pada perguruan tinggi akibat pandemi Covid-19 memberikan berbagai dampak pada mahasiswa, seperti penelitian Cao et al., (2020) menyebutkan bahwa Covid-19 berimbas pada ekonomi dan kehidupan sehari-hari termasuk aktivitas akademik, hal ini berhubungan dengan tingkat kecemasan mahasiswa di China. Penelitian United Nation Development Programme juga melaporkan bahwa Covid19 memiliki dampak terbesar pada keadaan finansial dan kesehatan mental mahasiswa di Thailand (UNDP et al., 2020). Copeland et al., (2021) berpendapat bahwa perguruan tinggi harus bersiap-siap menangani dampak pandemi pada kesehatan mental mahasiswa.

Dampak yang sama pada mahasiswa juga dilaporkan di Indonesia, diantaranya adalah mahasiswa mengalami stress, serta kurang kreatif dan produktif saat pembelajaran daring (Argaheni, 2020). Selain itu, dalam proses pembelajaran daring, mahasiswa mengalami kecemasan ringan, stress ringan, dan depresi ringan (Uswatun Hasanah, Ludiana, Immawati, 2020). Sejalan dengan hal tersebut, Harahap et al., (2020) juga menyatakan bahwa mahasiswa mengalami stress akademik pada kategori sedang. Laporan-laporan tersebut memberikan implikasi bahwa saat ini kesejahteraan mahasiswa tengah terganggu.

Dalam penelitian ini, konsep kesejahteraan dijelaskan dengan konsep kesejahteraan subjektif atau subjective wellbeing (SWB). Kesejahteraan subjektif merupakan suatu fenomena pada individu yang di dalamnya terdiri atas analisa tentang bagaimana individu mengevaluasi hidupnya, baik tentang kehidupannya dimasa kini atapun dimasa lalu, evaluasi ini meliputi reaksi seseorang terhadap suatu kejadian, suasana hatinya, dan penilaian tentang kepuasan hidupnya (Diener, 2000). Seseorang dikatakan memiliki kesejahteraan yang tinggi jika dia mengalami kepuasan hidup dan lebih sering mengalami kegembiraan, serta tidak terlalu sering mengalami emosi yang tidak menyenangkan, seperti kesedihan dan kemarahan. Sebaliknya, seseorang dikatakan memiliki kesejahteraan yang rendah jika dia tidak puas dengan hidupnya dan lebih sering mengalami emosi negatif seperti kemarahan atau kecemasan (Diener, 2000).

Terdapat beberapa penelitian terkait kesejahteraan subjektif dimasa pandemi Covid-19 seperti penelitian Y1ldırım \& Arslan (2020) yang menyatakan bawa harapan dan resiliensi individu memiliki hubungan langsung pada kesehatan psikologis dan kesejahteraan subjektif. Penelitian Wang et al., (2020) melaporkan bahwa kelompok yang melakukan lock down pada saat pandemi Covid-19 memiliki tingkat kesejahteraan subjektif yang rendah pada beberapa indikator. Laporan lainnya juga menyebutkan terdapat penurunan kesejahteraan pada mahasiswa dibandingkan dengan sebelum pandemi (Martínez et al., 2020). Di Indonesia sendiri, penelitian yang spesifik untuk mengetahui gambaran kesejahteraan subjektif mahasiswa dimasa pandemi Covid-19 masih belum banyak dilaporkan.

Terganggunya kesejahteraan subjektif individu dapat memunculkan berbagai dampak negatif, seperti individu dapat lebih sering merasakan emosi-emosi yang tidak menyenangkan (Diener et al., 2002). Sebaliknya, individu yang sejahtera memiliki hubungan dengan hal-hal positif, seperti lebih kreatif, optimis, kerja keras, dan tidak mudah putus asa (Diener, 2000). Individu yang sejahtera juga lebih bisa mengontrol emosinya dan menghadapi berbagai peristiwa hidup dengan baik (Diener, 2000). Dengan kata lain, berbagai manfaat dapat dirasakan jika individu 
merasa sejahtera. Oleh karena itu, diperlukan berbagai langkah kongkrit agar fenomena terganggunya kesejahteraan mahasiswa ditengah pandemi Covid-19 dapat ditangani dengan tepat. Pemerintah Indonesia memiliki konsen yang sama untuk menyikapi fenomena kesejahteraan mahasiswa yang terjadi di Indonesia, hal ini tertuang pada surat edaran nomor 4 tahun 2020 yang dikeluarkan oleh mentri pendidikan dan kebudayaan tentang pelaksanaan pendidikan dalam masa darurat penyebaran Covid-19 yang menyatakan bahwa pelaksanaan kebijakan pendidikan harus mengutamakan kesehatan lahir dan batin (Kemendikbud, 2020b).

Berdasarkan uraian di atas, maka diperlukan penelusuran lebih lanjut mengenai gambaran kesejahteraan mahasiswa selama pandemi Covid-19 agar fenomena kesejahteraan yang terjadi dapat dijelaskan dengan ilmiah. Gambaran tersebut diperlukan sebagai landasan informasi dalam menentukan tindakan yang tepat untuk memberdayakan dan mendukung kaum muda utamanya mahasiswa agar lebih tangguh dan adaptif selama dan pasca pandemi Covid-19. Selain itu, penelitian ini diharapkan mampu memberikan sumber informasi rujukan pendidikan tinggi untuk meningkatkan pelayanan kemahasiswaan yang berkaitan dengan kesejahteraan mahasiswa.

\section{METODE PENELITIAN \\ Partisipan Penelitian}

Penelitian ini dilakukan pada bulan Juni 2020. Partisipan penelitian ini adalah 112 mahasiswa yang melakukan pembelajaran daring ditengah pandemi Covid-19. Partisipan tersebar pada delapan pulau di Indonesia, adapun pengambilan pertisipan dilakukan dengan teknik accidiental sampling, Adapun sebaran responden dijabarkan pada tabel 1 .

Tabel 1. Sebaran Responden

\begin{tabular}{lll}
\multicolumn{1}{c}{ Pulau } & Jumlah \\
\hline Sumatera & 21 & \\
Kalimantan & 2 \\
Sulawesi & 1 &
\end{tabular}

\begin{tabular}{ll} 
Jawa & 85 \\
Nusa Tenggara Barat & 3 \\
\hline Jumlah Keseluruhan & 112 \\
\hline
\end{tabular}

\section{Instrumen Penelitian}

Instrumen kesejahteraan subjektif atau subjective well-being (SWB) pada penelitian ini diukur dengan merujuk konsep (Diener et al., 1999) yang memiliki empat dimensi, yaitu life satisfaction (LS), domain satisfaction (DS), positive affect (PA) dan negative affect (NA). Dimensi-dimensi tersebut diukur menggunakan Satisfaction With Life Scale (SWLS) oleh Diener et al., (1985) dan Positive and Negative Affect Scale (PANAS) oleh Watson \& Clark (1988), yang sudah diadaptasi ke dalam bahasa Indonesia.

Uji validitas alat ukur menggunakan Confirmatory Factor Analysis (CFA). Berdasarkan kriteria uji kecocokan yaitu chisquare diperoleh 1.49 (>0.05) dan RMSEA diperoleh $0.00 \quad(<0.05)$ maka dapat disimpulkan bahwa konstruk alat ukur good fit (Kline, 2015). Uji reliabilitas alat ukur dilakukan dengan melihat konsistensi internal diperoleh hasil 0.803 atau berdasarkan kriteria menurut Kaplan \& Saccuzzo (2017) alat ukur dapat diandalkan.

Skor responden pada alat ukur SWLS terbagi menjadi 1-5 dengan makna sangat tidak setuju hingga sangat setuju. Sedangkan skor alat ukur PANAS terbagi menjadi 1-5 dengan makna tidak pernah hingga sering sekali. Total skor kesejahteraan subjektif didapatkan dari mengurangi skor PA dengan skor NA kemudian menambahkannya dengan skor SWLS, penjumlahan ini konsisten dengan penelitian-penelitian sebelumnya mengenai SWB (Garcia \& Moradi, 2012; Jovanovic, 2011). Tingkat kesejahteraan subjektif ditentukan dengan mempertimbangkan skor tertinggi dan terendah dari data yang didapatkan, kemudian dibagi dengan jumlah rentang, atau dalam penelitian ini dibagi menjadi tiga yang terdiri dari tinggi, sedang, dan rendah. 


\section{Analisis Data}

Data penelitian dianalisis menggunakan metode deskriptif kuantitaif yang dianalisis secara univariat dan disajikan dengan frekuensi dalam bentuk tabel dan grafik.

\section{HASIL DAN PEMBAHASAN Hasil}

Tabel 2 dan Tabel 3 memperlihatkan gambaran usia dan jenis kelamin responden. Dapat disimpulkan bahwa penelitian ini diikuti responden dengan rata-rata umur 20 tahun dan lebih banyak diikuti oleh perempuan dari pada laki-laki.

Tabel 2. Usia Responden

\begin{tabular}{lll}
\hline $\mathrm{N}$ & Mean & SD \\
\hline 112 & 20.10 & 1.599 \\
\hline
\end{tabular}

Tabel 3. Jenis Kelamin Responden

\begin{tabular}{ll}
\hline Laki-laki & Perempuan \\
\hline $23,2 \%$ & $76,8 \%$ \\
\hline
\end{tabular}

Hasil deskripsi kesejahteraan subjektif dan dimensinya disajikan pada tabel 4. Sedangkan hasil kategorisasi kesejahteraan subjektif dan dimensinya disajikan pada tabel 5 dan grafik 1 .

\section{Tabel 4. Hasil Analisis Deskriptif}

\begin{tabular}{cccc}
\hline & Mean & Min & Max \\
\hline SWB & 16.27 & 6 & 25 \\
LS & 20.35 & 9 & 25 \\
DS & 39.61 & 20 & 50 \\
PA & 30.50 & 16 & 47 \\
NA & 45.72 & 13 & 76 \\
\hline
\end{tabular}

Tabel 5. Kategorisasi

\begin{tabular}{llll}
\hline & Kategori & $\mathrm{f}$ & $\%$ \\
\hline SWB & Tinggi & 32 & 28,6 \\
& Sedang & 60 & 53,6 \\
& Rendah & 20 & 17,9 \\
LS & Tinggi & 33 & 29,5 \\
& Sedang & 60 & 53,6 \\
& Rendah & 19 & 17,0 \\
DS & Tinggi & 72 & 64,3 \\
& Sedang & 36 & 32,1 \\
& Rendah & 4 & 3,6 \\
PA & Tinggi & 61 & 54,5 \\
\hline
\end{tabular}

\begin{tabular}{llll}
\hline & Sedang & 44 & 39,3 \\
& Rendah & 7 & 6,3 \\
NA & Tinggi & 30 & 26,8 \\
& Sedang & 41 & 36,6 \\
& Rendah & 41 & 36,6 \\
\hline
\end{tabular}

Grafik 1. Kategorisasi

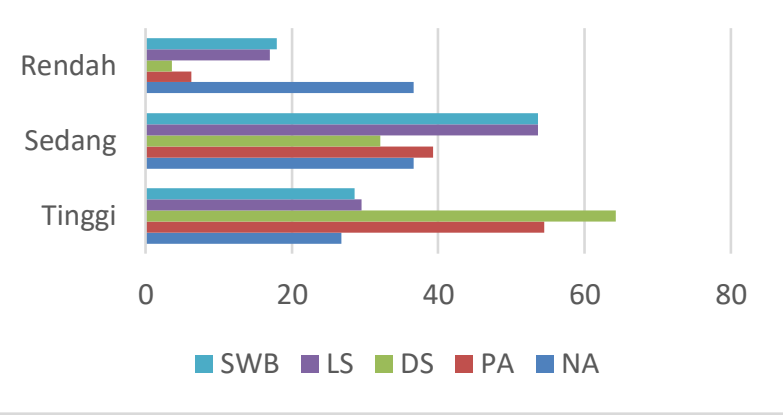

Berdasarkan tabel 5 dan grafik 1 dengan total responden 112 menunjukkan bahwa, mayoritas responden menunjukkan tingkat kesejahteraan subjektif pada kategori sedang $(53,6 \%)$, dimensi LS ada pada kategori sedang $(53,6 \%)$, dimensi DS ada pada kategori tinggi $(64,3 \%)$, dimensi PA ada pada kategori tinggi $(54,5 \%)$, namun pada dimensi NA menunjukkan kesamaan prosentase antara kategori sedang $(36,6 \%)$ dan rendah $(36,6 \%)$.

\section{Pembahasan}

Penelitian ini bertujuan untuk menggambarkan keadaan kesejahteraan subjektif mahasiswa dimasa pandemi Covid19. Data pada tabel 5 dan grafik 1 menyatakan bahwa secara keseluruhan, sebagian besar kesejahteraan subjektif responden ada pada kategori sedang, hal ini berarti responden mengevaluasi pengalaman dan emosi dalam hidupnya cukup positif. Penelitian ini dilakukan pada bulan Juni 2020, laporan Cheng et al., (2020) menyebutkan bahwa tren peningkatan kesejahteraan subjektif terjadi pada bulan Juni 2020 dan terus meningkat pada bulan Juli 2020.

Temuan lain dari data yang telah diperoleh pada tabel 5 dan grafik 1 menyatakan bahwa pada dimensi LS mayoritas responden berada pada kategori 
sedang, artinya responden merasa cukup puas dengan kehidupannya secara umum, kehidupan responden sudah cukup seperti apa yang diinginkan, kehidupannya cukup baik, cukup tidak ingin merubah masa lalunya, dan cukup mendapatkan apa yang diinginkannya. Temuan ini sama dengan temuan Rogwoska et al., (2020) yang menyatakan bahwa selama pandemi Covid19, sebagian besar mahasiswa di Poland merasa puas dengan hidupnya. Dimasa pandemi Covid-19, karakter individu memiliki hubungan dengan kepuasan hidup, seperti ketabahan, intelektualitas, dan kemampuan interpersonal terbukti meningkatkan kepuasan hidup individu (Martínez-Martí et al., 2020).

Tabel 5 dan grafik 1 juga menunjukkan bahwa pada dimensi DS mayoritas responden ada pada kategori tinggi, hal ini berarti responden puas pada domain yang ada dalam hidupnya, seperti puas berada ditengah-tengah keluarganya, bahagia saat terhubung dengan temantemannya, puas dengan kesehatannya, puas dengan uang saku atau pendapatanya, dan puas dengan waktu luangnya. Berkaitan dengan domain-domain tersebut, dapat dijelaskan dengan temuan-temuan berikut ini; yang pertama, berkaitan dengan domain keluarga dan teman-teman, menurut Ryan \& Deci (2017), lingkungan sosial seperti dukungan sosial memiliki peranan yang penting pada kesejahteraan individu. Dukungan sosial merupakan prediktor paling kuat yang dapat berkontribusi pada kesejahteraan subjektif (Gallagher \& VellaBrodrick, 2008). Praktik menjaga jarak selama pandemi Covid-19 memungkinkan individu untuk tetap di rumah bersama dengan keluarga, sebagian besar waktu yang dihabiskan di rumah tetap bisa membuat bahagia (Asanov et al., 2020). Selain itu, penggunaan teknologi selama pandemi Covid-19 memungkinkan individu untuk tidak kesepian dan dapat terhubung dengan relasi sosialnya (Saltzman et al., 2020). Kedua adalah domain yang berkaitan dengan kesehatan, melakukan aktivitas-aktivitas merupakan salah satu prediktor untuk tetap sehat secara fisik dan dapat meningkatkan kesejahteraan subjektif (Dury et al., 2021). Domain lainnya adalah uang saku atau penghasilan, terganggunya pendapatan dapat menurunkan kesejahteraan subjektif individu, namun guncangan sementara terhadap kekayaan tidak mempengaruhi kesejahteraan subjektif selama pandemi Covid-19 (D'Ambrosio et al., 2020). Domain terakhir adalah mengenai waktu luang, cara individu menghabiskan waktunya dapat menentukan kesejahteraan subjektif individu (Mogilner et al., 2018).

Kategori emosi positif responden ada pada kategori tinggi, sedangkan emosi negatif responden ada pada kategori sedang dapat dilihat pada tabel 1 dan grafik 1 . Hal ini berarti mayoritas responden sering merasakan emosi positif seperti sering bersemangat, kuat, antusias, bangga, terinspirasi, penuh perhatian, aktif berkegiatan, tertarik, dan waspada. Responden juga cukup merasakan emosi negatif seperti cukup merasa takut, tertekan, kesal, bersalah, bermusuhan, mudah tersingging, cemas, malu, gugup, dan gelisah. Terdapat hal-hal yang berhubungan dengan emosi yang dirasakan individu selama pandemi Covid-19, diantaranya adalah perbedaan individu dalam menilai suatu ancaman berhubungan negatif dengan emosi positif dan berhubungan positif dengan emosi negatif (Zacher \& Rudolph, 2020). Temuan lainnya menyatakan, walaupun Covid-19 membuat sebagaian besar idividu berkegiatan di rumah, namun terdapat berbagai kegiatan sehari-hari yang dapat membuat individu merasakan emosi positif seperti berolahraga, jalan-jalan, dan berkebun (Lades et al., 2020). Individu yang memiliki frekuensi berolahraga lebih banyak dimasa pandemi, dilaporkan lebih memiliki suasana hati yang baik, sebaliknya individu yang mengurangi frekuensi olahraga selama pandemi lebih memiliki suasana hati yang buruk (Brand et al., 2020). Selain itu, kekuatan karakter individu seperti ketabahan, kemampuan interpersonal, dan kemampuan menahan diri merupakan prediktor dalam menunkan emosi negatif 
selama pandemi Covid-19 (Martínez-Martí et al., 2020).

\section{KESIMPULAN}

Berdasarkan hasil penelitian, gambaran kesejahteraan subjektif mahasiswa selama pandemi Covid-19 adalah mayoritas ada pada kategori sedang $(53,6 \%)$, hal ini berarti mayoritas mahasiswa mengevaluasi pengalaman dan emosi dalam hidupnya cukup positif. Dimensi LS menunjukkan bahwa mayoritas mahasiswa juga ada pada kategori sedang $(53,6 \%)$, data tersebut memberikan implikasi bahwa mahasiswa sudah cukup puas dengan kehidupannya secara umum. Disisi lain, dimensi LD menunjukkan mayoritas mahasiswa ada pada kategori tinggi $(64,3 \%)$, yang berarti mahasiswa merasa puas dengan domaindomain yang ada pada hidupnya, seperti cukup puas dengan keluarga dan temannya, cukup puas dengan kesehatan, uang saku atau pendapatan, dan waktu luangnya. Selain itu, pada dimensi PA mayoritas mahasiswa juga berada pada kategori tinggi $(54,5 \%)$ yang berarti mahasiswa sering merasakan emosi-emosi positif, sedangkan untuk dimensi NA mayoritas mahasiswa berada pada kategori sedang dan rendah $(36,6 \%)$, artinya terdapat mahasiswa yang cukup sering merasakan emosi negatif dan jarang merasakan emosi negatif.

\section{Saran}

Secara umum, kesejahteraan subjektif mahasiswa di Indonesia berada pada kategori sedang, namun masih terdapat mahasiswa yang berada pada kategori rendah. Hal ini berarti masih terdapat mahasiswa yang mengevaluasi hidup dan emosinya secara negatif, yaitu masih terdapat mahasiswa yang tidak puas dengan hidupnya dan masih sering merasakan emosi negatif daripada emosi positif. Temuan ini dapat menjadi informasi kepada pihak perguruan tinggi bahwa dimasa pandemi Covid-19 diperlukan pelayanan mahasiswa yang mendorong peningkatakan kesejahteraan subjektif mereka, agar mahasiswa lebih tangguh dan adaptif dalam menghadapi kehidupan sehari-harinya baik selama pandemi Covid-19 maupun pasca pandemi Covid-19.

\section{DAFTAR PUSTAKA}

Argaheni, N. B. (2020). Sistematik Review: Dampak Perkuliahan Daring Saat Pandemi COVID-10 Terhadap Mahasiswa Indonesia. Placentum Jurnal Ilmiah Kesehatan Dan Aplikasinya, 8(2), 99-108.

Asanov, I., Flores, F., McKenzie, D., Mensmann, M., \& Schulte, M. (2020). Remote-learning, time-use, and mental health of Ecuadorian high-school students during the COVID-19 quarantine. World Development, 138. https://doi.org/10.1016/j.worlddev.2 020.105225

Brand, R., Timme, S., \& Nosrat, S. (2020). When Pandemic Hits: Exercise Frequency and Subjective WellBeing During COVID-19 Pandemic. Frontiers in Psychology, 11, 2391. https://doi.org/10.3389/fpsyg.2020. 570567

Cao, W., Fang, Z., Hou, G., Han, M., Xu, X., Dong, J., \& Zheng, J. (2020). The psychological impact of the COVID-19 epidemic on college students in China. Psychiatry Research, 287, 112934. https://doi.org/10.1016/j.psychres.2 020.112934

Cheng, T. C., Kim, S., \& Koh, K. (2020). The Impact of COVID-19 on Subjective Well-Being: Evidence from Singapore. www.iza.org

Copeland, W. E., McGinnis, E., Bai, Y., Adams, Z., Nardone, H., Devadanam, V., Rettew, J., \& Hudziak, J. J. (2021). Impact of COVID-19 Pandemic on College Student Mental Health and Wellness. Journal of the American Academy of Child and Adolescent Psychiatry, 60(1), 134-141.e2. https://doi.org/10.1016/j.jaac.2020. 08.466 
D’Ambrosio, C., Jäntti, M., \& Lepinteur, A. (2020). Money and Happiness: Income, Wealth and Subjective Well-Being. Social Indicators Research, 148(1), 47-66. https://doi.org/10.1007/s11205-01902186-w

Diener, E. (2000). Subjective well-being: The science of happiness and a proposal for a national index. American Psychologist, 55(1), 3443. https://doi.org/10.1037/0003066X.55.1.34

Diener, E., Emmons, R. A., Larsem, R. J., \& Griffin, S. (1985). The Satisfaction With Life Scale. Journal of Personality Assessment, 49(1), 7175.

https://doi.org/10.1207/s15327752j pa4901_13

Diener, E., Lucas, R. E., \& Oishi, S. (2002). Subjective well-being: The science of happiness and life satisfaction. In Handbook of positive psychology (pp. 63-73).

Diener, E., Suh, E. M., Lucas, R. E., \& Smith, H. L. (1999). Diener, Suh, Lucas \& Smith (1999).pdf. In Psychological Bulletin (Vol. 125, pp. 276-302). https://doi.org/10.1037/00332909.125.2.276

Dury, S., Stas, L., Switsers, L., Duppen, D., Abella, J. D., Dierckx, E., \& Donder, L. De. (2021). Genderrelated differences in the relationship between social and activity participation and health and subjective well-being in later life. Social Science \& Medicine, 270, 113668.

https://doi.org/10.1016/j.socscimed. 2020.113668

Gallagher, E. N., \& Vella-Brodrick, D. A. (2008). Social support and emotional intelligence as predictors of subjective well-being. Personality and Individual Differences, 44(7), 1551-1561. https://doi.org/10.1016/j.paid.2008.

\subsection{1}

Garcia, D., \& Moradi, S. (2012). Adolescents' Temperament and Character: A Longitudinal Study on Happiness. Journal of Happiness Studies, 13(5), 931-946. https://doi.org/10.1007/s10902-0119300-8

Harahap, A. C. P., Harahap, D. P., \& Harahap, S. R. (2020). Analisis Tingkat Stres Akademik Pada Mahasiswa Selama Pembelajaran Jarak Jauh Dimasa Covid-19. Biblio Couns: Jurnal Kajian Konseling Dan Pendidikan, 3(1), 10-14.

Jovanovic, V. (2011). Personality and subjective well-being: One neglected model of personality and two forgotten aspects of subjective well-being. Personality and Individual Differences, 50(5), 631635. https://doi.org/10.1016/j.paid.2010. 12.008

Kaplan, R. M., \& Saccuzzo, D. P. (2017). Psychological Testing: Principles, Applications, and Issues. Nelson Education.

Kemendikbud. (2020a). Kemendikbud Dorong Pembelajaran Daring Bagi Kampus Di Wilayah Terdampak Covid-19.

Kemendikbud. (2020b). Penyesuaian Kebijakan Pembelajaran di Masa Pandemi Covid-19. https://bersamahadapikorona.kemdi kbud.go.id/presentasi/

Kline, R. B. (2015). Principles and Practice of Structural Equation Modeling. Guilford Publications.

Lades, L. K., Laffan, K., Daly, M., \& Delaney, L. (2020). Daily emotional well-being during the COVID-19 pandemic. British Journal of Health Psychology, 25(4), 902-911. https://doi.org/10.1111/bjhp.12450

Martínez-Martí, M. L., Theirs, C. I., Pascual, D., \& Corradi, G. (2020). Character Strengths Predict an Increase in 
Mental Health and Subjective WellBeing Over a One-Month Period During the COVID-19 Pandemic Lockdown. Frontiers in Psychology, 11.

Martínez, L., Valencia, I., \& Trofimoff, V. (2020). Subjective wellbeing and mental health during the COVID-19 pandemic: Data from three population groups in Colombia. Data in Brief, 32. https://doi.org/10.1016/j.dib.2020.1 06287

Mogilner, C., Whillans, A., \& Norton, M. I. (2018). Time, Money, and Subjective Well-Being. In In $E$. Diener, S. Oishi, \& L. Tay (Eds.), Handbook of Well-Being. UT: DEF publishers.

Rogwoska, A. M., Kusnierz, C., \& Bokszczanin, A. (2020). Examining Anxiety, Life Satisfaction, General Health, Stress and Coping Styles During COVID-19 Pandemic in Polish Sample of University Students. Psychology Research and Behavior Management, 13, 797811.

https://doi.org/10.2147/PRBM.S266 511

Ryan, R. M., \& Deci, E. L. (2017). Selfdetermination theory: Basic psychological needs in motivation, development, and wellness. Guilford Publications.

Saltzman, L. Y., Hansel, T. C., \& Bordnick, P. S. (2020). Loneliness, Isolation, and Social Support Factors in PostCOVID-19 Mental Health. Psychological Trauma: Theory, Research, Practice, and Policy, 12, 55-57. https://doi.org/10.1037/tra0000703

UNDP, UNICEF, \& UNFPA. (2020). Preliminary Report: Survey on Impacts of COVID-19 Pandemic on Children and Young People and Their Needs. In Preliminary Report. https://doi.org/10.1155/2010/70687 2
UNESCO. (2020). 1.3 billion learners are still affected by school or university closures, as educational institutions start reopening around the world, says UNESCO.

Uswatun Hasanah, Ludiana, Immawati, L. P. (2020). Gambaran Psikologis Mahasiswa Dalam Proses Pembelajaran Selama Pandemi COVID-19. Jurnal Keperawatan Jiwa, 8(3), 299-306.

Wang, Y., Wu, P., Liu, X., Li, S., Zhu, T., \& Zhao, N. (2020). Subjective wellbeing of Chinese Sina Weibo users in residential lockdown during the COVID-19 pandemic: Machine learning analysis. Journal of Medical Internet Research, 22(12), e24775.

https://doi.org/10.2196/24775

Watson, D., \& Clark, L. A. (1988). Development and Validation of Brief Measures of Positive and Negative Affect: The PANAS Scales. Journal of Personality and Social Psychology, 54(6), 10631070.

WHO. (2020). Coronavirus disease (COVID-19) pandemic.

Y1ldırım, M., \& Arslan, G. (2020). Exploring the associations between resilience, dispositional hope, preventive behaviours, subjective well-being, and psychological health among adults during early stage of COVID-19. Current Psychology, 1-11. https://doi.org/10.1007/s12144-02001177-2

Zacher, H., \& Rudolph, C. W. (2020). Individual Differences and Changes in Subjective Wellbeing During the Early Stages of the COVID-19 Pandemic. American Psychologist, 76(1), 50-62. https://doi.org/10.1037/amp000070 2 